\title{
The influence of the injection frequency on the urea selective catalytic reduction systems performance
}

This study presents the influence of the UWS injection frequency on a close coupled SCR systems performance. The investigation was performed with the CFD tool AVL Fire. In the paper the analysis of four different UWS injection frequencies in the three different operating points of diesel engine was shown. The assessments of the system performance was referred to the ammonia distribution at catalyst intake and wall film formation inside the investigated geometry, as these are considered as crucial in such a configuration. The results showed that injection frequency affects both factors on different level depending from the flow conditions. In addition, the wall film crystallization risk was discussed basing on the obtained wall film characteristics.

Key words: AVL FIRE, selective catalytic reduction, uniformity index, UWS, wall-film

\section{Introduction}

The SCR is the most widely used technique for nitrogen oxides control in the automotive industry. Successive emission regulations put increasingly stringent limits on $\mathrm{NO}_{\mathrm{x}}$ content in an exhaust gases. Those restrictions are especially demanding for a diesel engines, for which $\mathrm{NO}_{\mathrm{x}}$ emission was reduced over $85 \%$ in Europe, compering the Euro 5 and Euro 6 standards [1]. Thus, the SCR systems are objects of intensive research work.

The urea-water-solution (UWS), containing $32.5 \%$ of the urea, is injected directly in to the hot exhaust gas stream. The reducing agent ammonia $\left(\mathrm{NH}_{3}\right)$ is produced by UWS decomposition described by three steps [2]:

1. Evaporation of water,

$$
\left(\mathrm{NH}_{2}\right)_{2} \mathrm{CO}(\mathrm{aq}) \rightarrow\left(\mathrm{NH}_{2}\right) \mathrm{CO}(\mathrm{s} \text { or } 1)+6.9 \mathrm{H}_{2} \mathrm{O}(\mathrm{g})
$$

2. Thermolysis of urea into ammonia and isocyanic acid,

$$
\left(\mathrm{NH}_{2}\right) \mathrm{CO}(\mathrm{s} \text { or } \mathrm{l}) \rightarrow\left(\mathrm{NH}_{3}\right)(\mathrm{g})+\mathrm{HNCO}(\mathrm{g})
$$

3. Hydrolysis of isocyanic acid,

$$
\mathrm{HNCO}(\mathrm{g})+\mathrm{H} 2 \mathrm{O}(\mathrm{g}) \rightarrow \mathrm{NH}_{3}(\mathrm{~g})+\mathrm{CO}_{2}(\mathrm{~g})
$$

Subsequently passing through these three steps $1 \mathrm{~mol}$ of the urea generates 2 mols of ammonia. The UWS mass flow is usually determined to give the same number of $\mathrm{NH}_{3}$ and NOx mols upstream the catalyst.

The typical diesel after-treatment system, to meet last regulations, consist of Diesel Oxides Catalyst (DOC), Diesel Particular Filter (DPF) and SCR in different configurations. However, as further even stringent emission restrictions are expected, an improvement of this particular technology could be challenging. The newest approach is to combine the DPF and SCR functions by wash-coating the SCR on the DPF, what is called SCRoF (Selective Catalytic Reduction on Filter). Due to the fact, that such a solution occupied less space it can be placed closer to the engine, what reduces thermal loses, backpressure, packaging space, weight and costs at least [3]. On the other hand, the placement of the systems and its packaging results in smaller space for the UWS decomposition and mixing what directly affects the main benchmark of the SCR systems which is even ammonia distribution at catalyst intake described by Uniformity Index (UI). The common solution to improve the ammonia UI is installing a static mixing device, which generates swirls before SCRoF. Nevertheless, it means that spray-wall interactions should be expected, therefore undesired by-products like biuret, cyanuric acid, melamine and ammeline could occur and form solid deposit. The urea crystallization can lead to decreased SCR systems efficiency and higher ammonia slip simultaneously. What is more, the formed deposit results in higher backpressure, and in highly unfavorable conditions may log whole system and simply destroy it [4]. Due to the above, the knowledge about urea wall-film formation risk, uniformity index and pressure drop is crucial already at early stage of the product development process.

Number of research works proof usefulness of the Computational Fluid Dynamics (CFD) tools for a SCR applications. For instance it was shown that a numerical simulations could be used for developing the static mixers design in case of an ammonia distribution and a pressuredrops [5], an assessment of the spray-wall interaction [6] and an UWS injection [7]. Moreover, CFD tools offer functionality, cost effectiveness and increasing credibility. At the early stage of the product development, when a variety of a different concepts and configurations are taken into consideration, CFD calculations helps to choose the most promising design, or upgrade already existing idea. Therefore, it is widely used in automotive industry.

In this work, investigation into SCR systems performance using numerical simulations was carried out. Within the presented paper, the influence of the injection frequency on the ammonia distribution and wall-film formation was analyzed. Considered geometry refers to the DOC+SCRoF architecture in the close coupled solution. The calculations were conducted for variety of flow conditions corresponding to the different exhaust mass flow of the diesel engine.

\section{Geometry and numerical setup}

For the comparison purposes four different injection frequencies from $1 \mathrm{~Hz}$ up to $8 \mathrm{~Hz}$, for three different exhaust gases mass flow rates corresponding to idle, light and medium load of diesel engine were calculated. The results 
for $4 \mathrm{~Hz}$ injection were treated as the reference value in each condition. The full matrix of the calculations is shown in the Table 1.

Table 1. Calculations matrix

\begin{tabular}{|c|c|c|c|c|}
$\begin{array}{r}\text { Injection } \\
\text { Frequency } \\
\text { Point }\end{array}$ & $1 \mathrm{~Hz}$ & $2 \mathrm{~Hz}$ & $4 \mathrm{~Hz}$ & $8 \mathrm{~Hz}$ \\
\hline Idle & Case 1 & Case 2 & Case 3 & Case 4 \\
\hline Light & Case 5 & Case 6 & Case 7 & Case 8 \\
\hline Medium & Case 9 & Case 10 & Case 11 & Case 12 \\
\hline
\end{tabular}

The geometry resembles typical closed coupled solution for light duty vehicles with the cylindrical DOC and SCRoF connected by transfer cone. The inlet section of the DOC was extruded by $10 \mathrm{~cm}$ in order to make so called dummy inlet which provided stable flow at catalyst intake, the same operation was repeated on the SCRoF outlet, where $10 \mathrm{~cm}$ long dummy outlet was created. In the middle of the transfer cone static mixer device is placed. The injector is located at the top of the section and its axis passes through the mixer. Whole geometry setup is shown in the Fig. 1.

The computational mesh (Fig. 1) was built by hexahedral elements in a few steps. Firstly, the transfer cone was meshed, using the AVL Fame Hexa tool, with base size of the elements equal to $3 \mathrm{~mm}$. Due to the irregular shape of the design, the injector and mixer section were refined by $1.5 \mathrm{~mm}$ and $0.75 \mathrm{~mm}$ cell respectively. The DOC mesh were extruded from the inlet selection of the transfer cone and afterwards dummy inlet from the DOC. The same

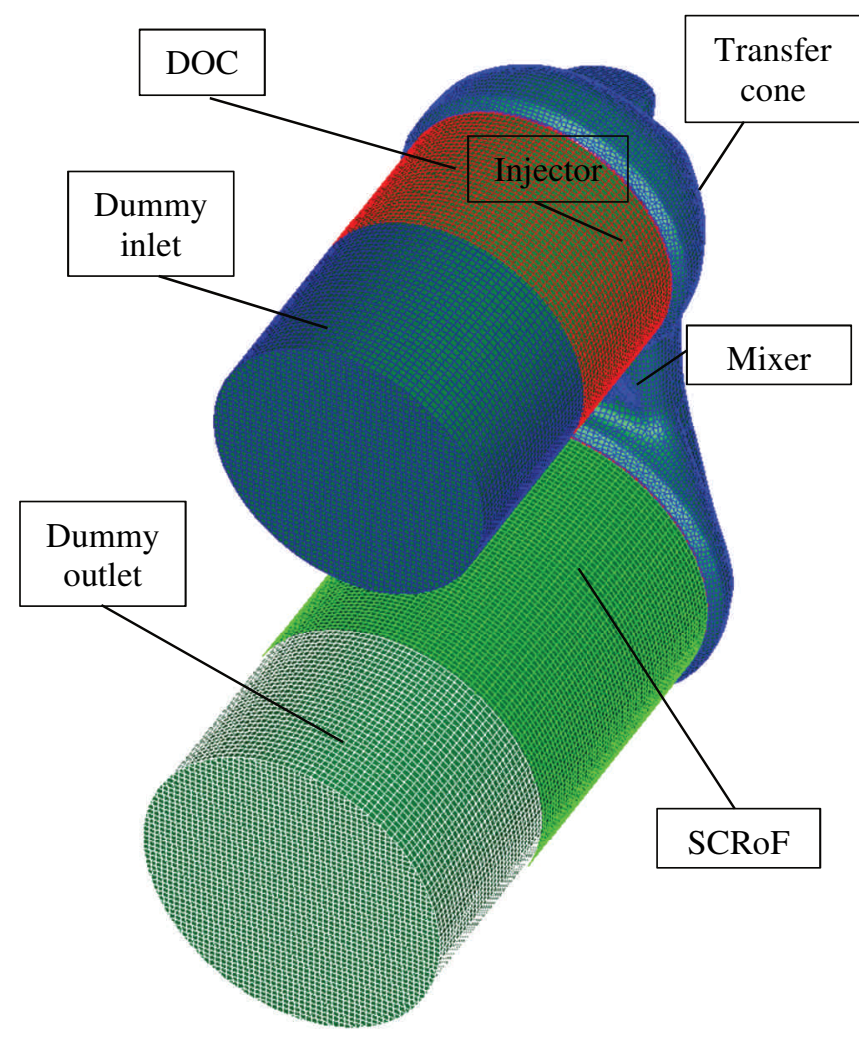

Fig. 1. The geometry and mesh meshing strategy was applied to the SCRoF and dummy outlet. Thanks to this meshing methodology the structural grid before and after transfer cone was obtained and moreover conformal matching of the parts was possible. Finally, the total size of the domain was equal to 643132 cells.

All of the simulations were conducted using the AVL Fire 2014.2 CFD software, with Species Transport, General Gas Phase Reactions, Porosities, Spray and Wallfilm modules activated. The flow, consisted of diesel combustion products: $\mathrm{CO}_{2}, \mathrm{CO}, \mathrm{H}_{2} \mathrm{O}, \mathrm{O}_{2}, \mathrm{NO}, \mathrm{NO}_{2}, \mathrm{~N}_{2}$ was treated as compressible and turbulent. Timestep was set to $\mathrm{dt}=5 \mathrm{~ms}$ and $\mathrm{dt}=0.5 \mathrm{~ms}$ for the flow when injection did not occur and for injection time, respectively. All walls were treated as adiabatic, static pressure outlet was set for the outlet selection.

Both, DOC and SCRoF were modeled as the direct porous media zones. The pressure drop for them were calculated from the Forchheimer formula [8] which described pressure drop as a linear viscous loses corrected by quadratic inertial loses in the function of the velocity inside the zone. Note that, the porous media zones were used only to obtain desirable pressure drops and flow distribution. The chemistry inside the catalyst was not included as it does not have impact on specific objectives of this work.

The UWS spray was represented using the Discrete Droplet Method (DDM). In this approach droplets of the similar size and properties are grouped in the parcels and as a unity treated in the equations. For the UWS decomposition the Birkhold model was used [2], in which it is assumed that urea decompose through thermolysis directly from the solid or liquid phase and its evaporation could be neglected. Thus, due to the fact that water has lower boiling temperature than urea, the model assumed that firstly water evaporates until in droplet remains only urea (1) and then thermolysis occurs (2) [9]. The influence of the dissolved urea in the water on its evaporation rate is modeled basing on Aramzon-Sirignano approach, where heat mass transfer of each component is taken account separately, while heat transfer is a global mechanism [9]. It is assumed that there is no urea crystallization and droplet remain spherical through evaporation. Finally, the hydrolysis of the HNCO into ammonia (eq. 3) is resolved by General Gas Phase reaction module with CHEMKIN input chemistry. The UWS injection is realized by three nozzle commercial injector, which works under the pressure of 4 bar with static the mass flow of $1 \mathrm{~g} / \mathrm{s}$. As the spray is represented with the DDM method, the volume based Rosin-Rammler distribution were applied. The dosing of the UWS were recalculated for each operating condition for keeping constant ammonia to $\mathrm{NO}_{\mathrm{x}}$ ratio, the injected mass was controlled by duration of the injection. The injection was started after $0.3 \mathrm{~s}$ from the simulation start, when the flow was fully developed.

Spray-wall interaction was implemented with AVL Fire Wallfilm module. With this approach Kuhnke model is implemented, hence software distinguishes four interactions regimes basing on dimensionless droplet velocity and dimensionless wall and saturation temperature ratio. With those quantities dependences rebound, thermal breakup, deposition or splash could occur [10]. 
For the turbulent conditions the k-zeta-f model was chosen. This model, developed Hanjalic et al. [11, 12], according to the authors, improves the numerical stability of the origin model by solving the velocity scale ratio $\overline{v^{2}} / \mathrm{k}$ transport equation instead of velocity scale $\overline{v^{2}}$. Due to the more convenient formulation of the equation it is more robust and less sensitive to non-uniformities and clustering of the computational grid [13].

\section{Results and discussion}

\subsection{Ammonia distribution}

The pictures presented below (Figures 2-4) show the comparison of the time averaged ammonia uniformity index at the SCRoF inlet for set of the injection frequency in each operating condition. The distinct dependency between UWS injection frequency and the course of the uniformity over the time can be seen for idle operating point (Fig. 2). Here, along with the injection frequency increase the value of the uniformity index is respectively smaller in whole range of the simulation time. At the end of the simulation

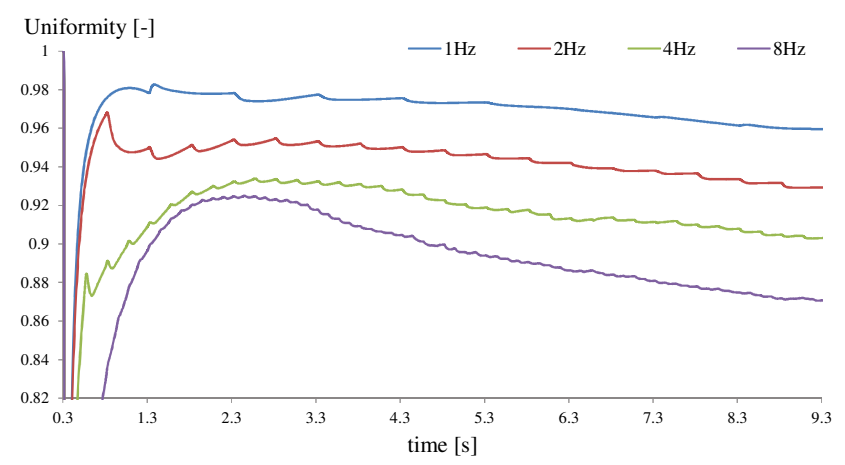

Fig. 2. Uniformity index at SCRoF inlet for idle load

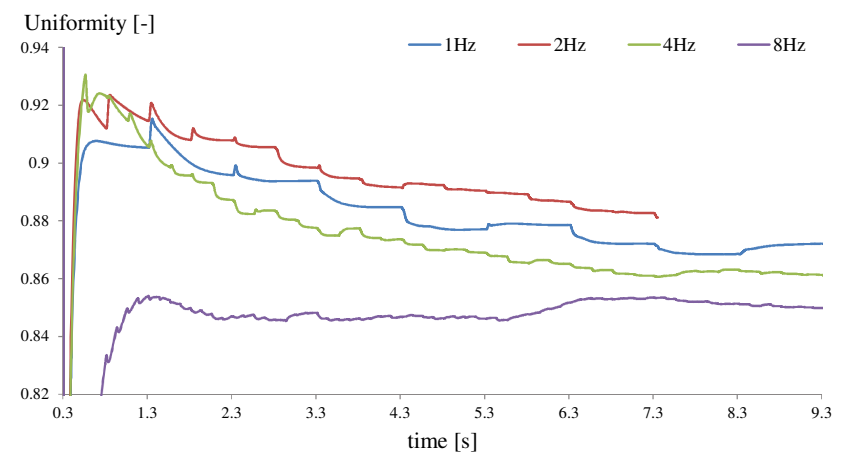

Fig. 3. Uniformity index at SCRoF inlet for light load

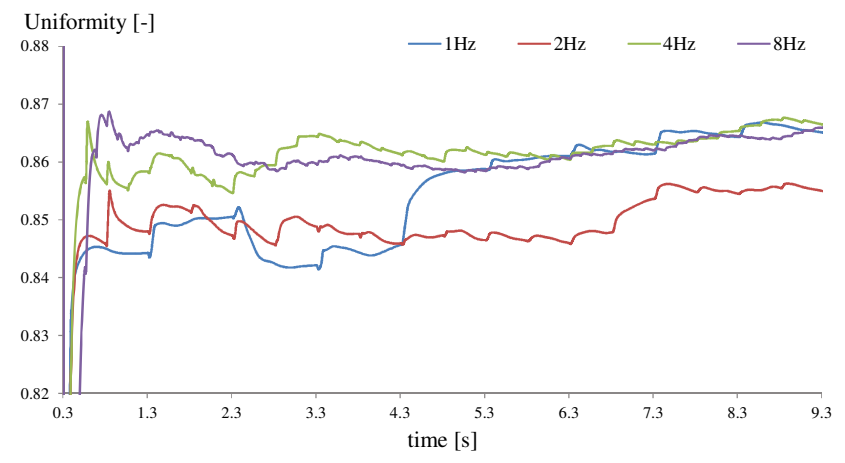

Fig. 4. Uniformity index at SCRoF inlet for medium load the difference between extreme values is equal approximately $10 \%$. Moreover, the higher rate of rise of the graph after first injection could be noticed for the lower injector frequencies.

The observed dependencies for idle conditions are not so apparent for light and medium loads. Figure 3 shows that the differences in final uniformity result decreasing, in comparison with idle load, and the maximum deviation is circle about $4 \%$. It is also characteristic for this graph that the best performance is given by $2 \mathrm{~Hz}$ injector. Despite the fact that calculations for $2 \mathrm{~Hz}$ injector were conducted for shorter time, it was assumed that the general trend of the line should be kept up to $9.3 \mathrm{~s}$.

For the middle engine load (Fig. 4), the uniformity index graphs convergence to the approximately same value, with the exception of $2 \mathrm{~Hz}$ injector line, which again distinguish at the overall trend. Nevertheless, the difference does not exceed $1 \%$, hence it is legitimatized to claim that the distinction between final results declines with higher combustion products and UWS mass flow through the system.

\subsection{Wall film formation}

Next analysis refers to the wall film formation. Figures 5-7 depict accumulated total film mass on the transfer cone walls, including mixer device. It could be noticed that with higher injection frequency, the wall film fluctuations have smaller amplitude. For the idle engine load (Fig. 5) the dependencies are clear, the extreme points of one injection pulse of the higher frequency are placed inside the lower frequencies. It is also visible that regardless of case the total amount of wall film at the ends of the injection cycle is close to zero. The situation is slightly different for further engine loads. At the Figure 6 one can observe that $8 \mathrm{~Hz}$ case does not fit overall trend. The maximum points in each cycle are above maximums of $4 \mathrm{~Hz}$ injector. It means that due to short time between subsequent injections capability of the evaporation from the walls was exceed compering to the lower frequencies. The confirmation of this conclusion could be found at the medium load wall film graph (Fig. 7), where even local minimums of the $8 \mathrm{~Hz}$ curve cross $4 \mathrm{~Hz}$ curve at the end of the simulation. It could be also deducted from the graphs behaviour that with longer computational time $2 \mathrm{~Hz}$ case extreme points will lie under the $8 \mathrm{~Hz}$ case for medium operating point. What is also distinctive, lower frequencies give better wall film performance. As shown at the Fig. 6, $1 \mathrm{~Hz}$ case, as the only one, reaches values near zero at the ends of injection pulses.

Nevertheless, in the conducted numerical research, no wall film crystallization model was applied, hence wall film mass could not be treated as only benchmark in those cases. As it is shown at Figures 5-7, despite the fact that with lower frequency less wall film is deposited at walls at the end of the each cycle, the attention also ought to be pay for maximum points. Those peaks could be responsible for local wall cooling and crystallization as the consequence. Therefore, in order to better assessment of the risk, additional Film coefficient (FC), given by equation (4), describing the mass concentration at wall surface, was introduced.

$$
\mathrm{FC}=\frac{\text { Wallfilm }}{\text { mass }}\left[\frac{\mathrm{mg}}{\mathrm{mm}^{2}}\right]
$$




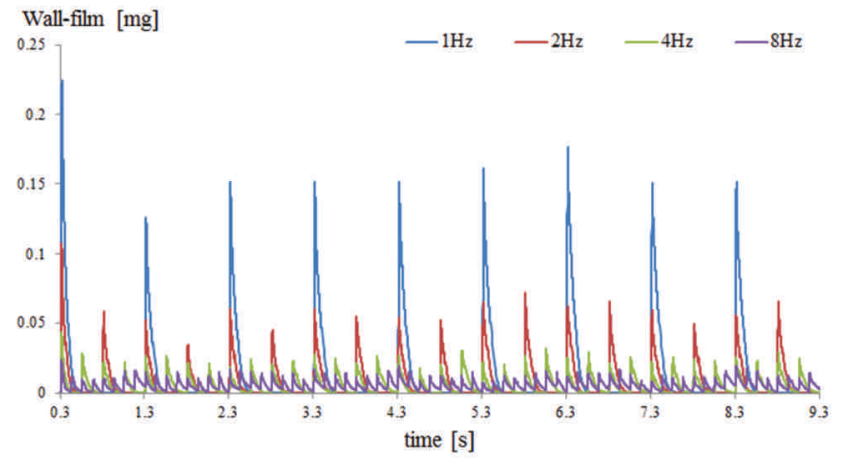

Fig. 5. Total wall film mass for idle load

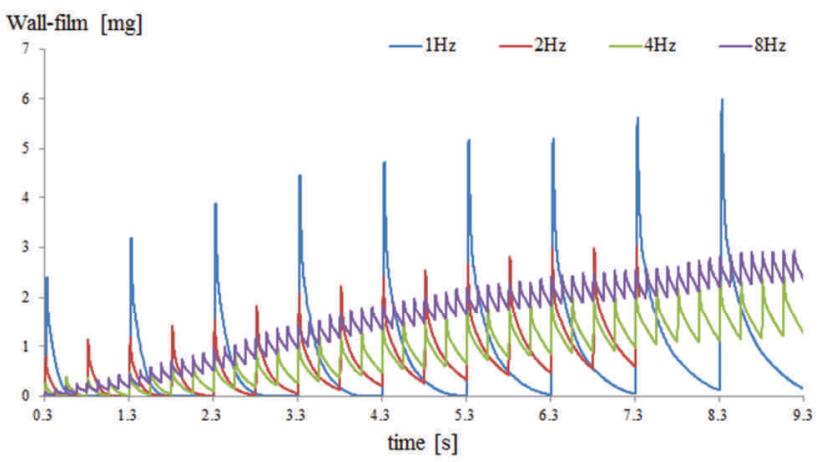

Fig. 6. Total wall film mass for light load

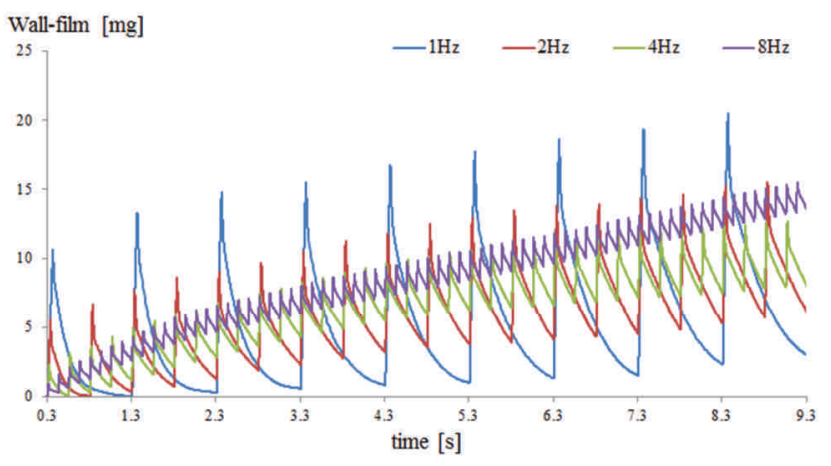

Fig. 7. Total wall film mass for medium load

Figures 8-10 presents FC course over the time in each operating condition. For the idle condition (Fig. 8), due to the small UWS flow the graphs behave in stochastic way and it could be say that mean values of the coefficient in calculated cases are approximately equal. Next, the values for the idle conditions are at the similar order magnitude with those from the light and medium operating point (Figs 9-10). The explanation among other could be that for the lower operating point the momentum of the gas is not high enough to influence the spray droplets, hence only the area in the spray direction is affected by the spray. On the other hand, along with mass flow increase more droplets are taken by the stream, thus wall film is distributed on the bigger area. For this series it is also visible that FC amplitude decreases with the time, and purses to the quasi stable value.

The risk of the wall film crystallization could be directly associate with value of the FC, as more heat will be taken from the same unit of the surface. Basing on the graphs, independently from the operating point, due to the highest

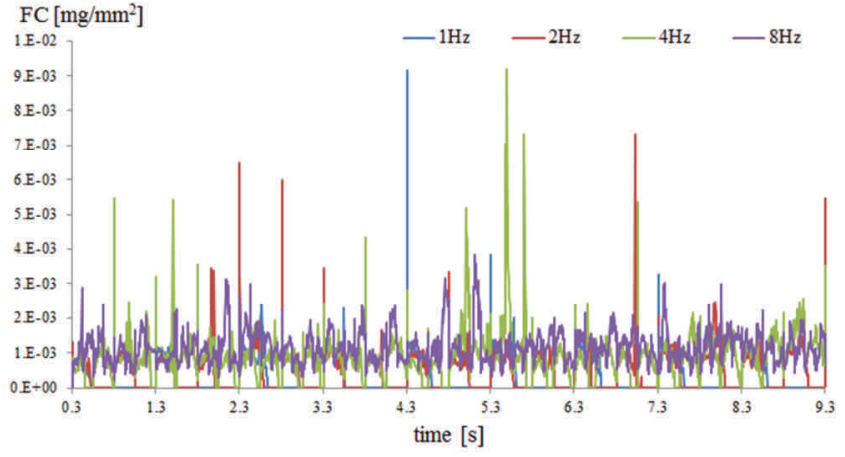

Fig. 8. Film coefficient for idle load

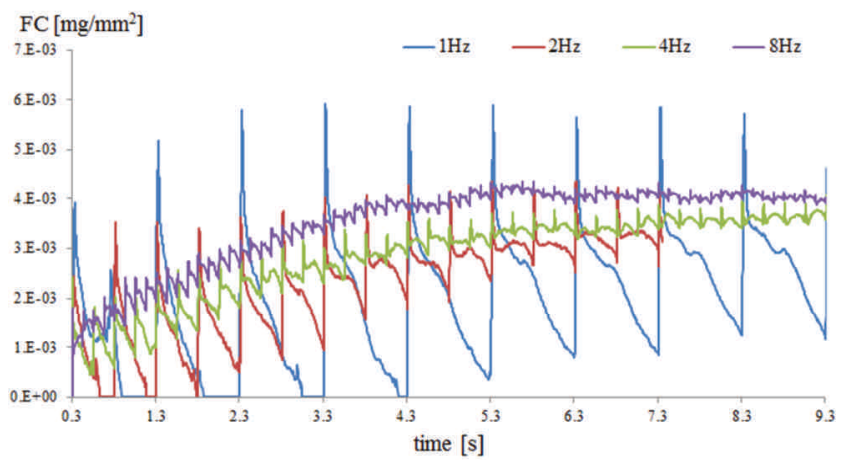

Fig. 9. Film coefficient for light load

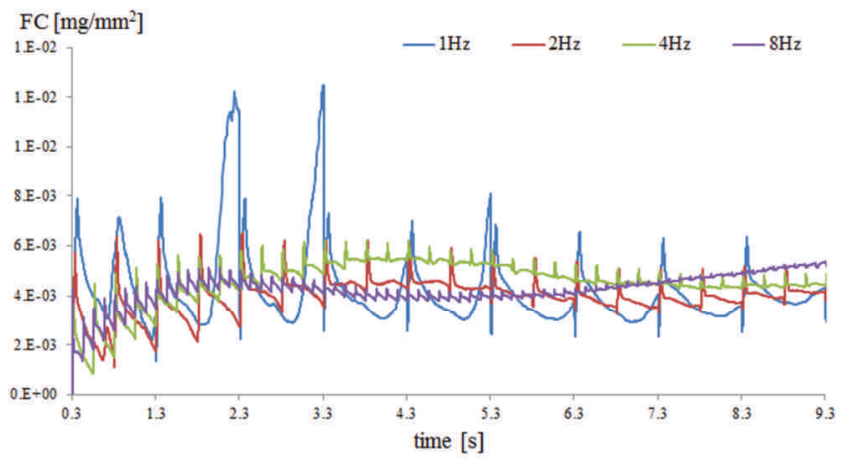

Fig. 10. Film coefficient for medium load

peaks, the bigger risk comes from the $1 \mathrm{~Hz}$ frequency, and then from the $8 \mathrm{~Hz}$.

\section{Conclusions}

This paper presents the numerical research of the close coupled SCRoF and numerical capabilities of simulating physical phenomena occurring in such systems . The influence of the injection frequency on the SCR system performance was investigated for different diesel engine operating conditions corresponding to idle, light and medium load of diesel engine. The analysis referred to the ammonia distribution at SCR inlet and wall film formation on the SCR system walls including mixing device.

The results showed that, especially for the idle and light engine loads, the best UI index is given by low frequency injections. The differences could be up to $10 \%$, what is quite big amount when considering that engineers and designers put a lot of effort for each one percent of UI value. What is more, wall film analysis indicates that for the idle operating point the risk of the wall film crystallization 
ought to be approximately same for each injection frequency. Nevertheless, for rest of the simulated operating points, research showed distinctly that lowest frequency gave the higher crystallization risk.

\section{Acknowledgements}

Current work was supported by the European Smart Growth Operational Programme 2014-2020 through the project "Development of mixing and urea-water solution conversion unit in SCR systems in order to start production of exhaust system for compression ignition engine that meets the Euro 7 emission standards", number POIR.04.01.04-00-0060/15-02.

This work has been done under AVL University Partnership Program.

\section{Nomenclature}

CFD computational fuid dynamic

DDM discrete droplet method

DOC diesel oxidation catalyst

DPF diesel particulate filter

FC film coeficient
SCR selective catalytic reduction

SCRoF selective catalytic reduction on filter

UI uniformity index

UWS urea water solution

\section{Bibliography}

[1] European Union, REGULATION (EC), 2007, 715.

[2] BIRKHOLD, F., MEINGAST, U., WASSERMANN, P., DEUTSCHMANN, O. Modeling and simulation of the injection of urea-water-solution for automotive SCR DeNOxsystems. Appl. Catal. B Environ. 2007, 70(1-4), 119-127.

[3] GUAN, B., ZHAN, R., LIN, H., HUANG, Z. Review of state of the art technologies of selective catalytic reduction of $\mathrm{NO}_{\mathrm{x}}$ from diesel engine exhaust. Appl. Therm. Eng. 2014, 66(1-2), 395-414.

[4] BRACK, W. et al. Kinetic modeling of urea decomposition based on systematic thermogravimetric analyses of urea and its most important by-products. Chem. Eng. Sci. 2014, 106, $1-8$.

[5] SUNG, Y., CHOI, C., KIM, T. et al. Effect of geometric structure of static mixers on mixing characteristics and pressure drop in marine SCR applications. 2013, 2, 1-7.

[6] NOCIVELLI, L., MONTENEGRO, G., LIAO, Y. et al. Modeling of aqueous urea solution injection with characteri-
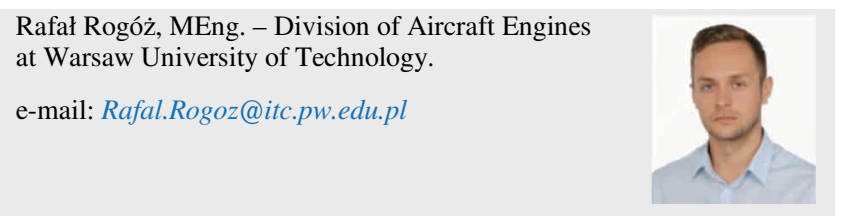

Piotr Jaworski, MEng. - Division of Aircraft Engines at Warsaw University of Technology.

e-mail: Piotr.Jaworski@itc.pw.edu.pl

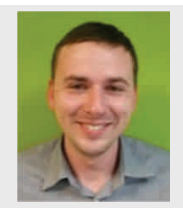

zation of spray-wall cooling effect and risk of onset of wall wetting. Energy Procedia. 2015, 82, 38-44.

[7] STRÖM, H., LUNDSTRÖM, A., ANDERSSON, B. Choice of urea-spray models in CFD simulations of urea-SCR systems. Chem. Eng. J. 2009, 150(1), 69-82.

[8] AVL Fire ${ }^{\circledR}$ version 2014.2. Porous Module. 2014.

[9] AVL Fire ® version 2014.2. Spray Module. 2014.

[10] AVL Fire ${ }^{\circledR}$ version 2014.2. Wallfilm Module. 2014.

[11] HANJALIĆ, K., POPOVAC, M., HADŽIABDIĆ, M. A robust near-wall elliptic-relaxation eddy-viscosity turbulence model for CFD. Int. J. Heat Fluid Flow. 2004, 25(6), 1047-1051.

[12] POPOVAC, M., HANJALIC, K. Compound wall treatment for RANS computation of complex turbulent flows and heat transfer. Flow, Turbul. Combust. 2007, 78(2), 177-202.

[13] KAPUSTA, Ł.J., TEODORCZYK, A. Numerical simulations of a simultaneous direct injection of a liquid and gaseous fuel into constant volume chamber. J. Power Technol. 2012, 92(1), 12-19.

\footnotetext{
Łukasz Jan Kapusta, DEng. - Faculty of Power and Aeronautical Engineering at Warsaw University of Technology.

e-mail: Lukasz.Kapusta@itc.pw.edu.pl
}

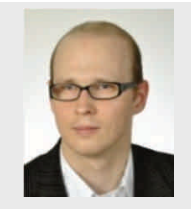

Prof. Andrzej Teodorczyk, DSc., DEng. - Faculty of Power and Aeronautical Engineering at Warsaw University of Technology.

e-mail: Andrzej.Teodorczyk@itc.pw.edu.pl 